\title{
Management of COPD exacerbations in primary care: a clinical cohort study
}

\section{*Josefin Sundh1, Eva Österlund Efraimsson ${ }^{2 \dagger}$, Christer Janson ${ }^{3}$, Scott Montgomery ${ }^{4,5}$, Björn Ställberg ${ }^{6}$, Karin Lisspers ${ }^{6}$}

\author{
'Department of Respiratory Medicine, Örebro University Hospital \& School of Health and Medical Science, Örebro University, 70185 Örebro, \\ Sweden \\ 2 School of Health and Social Studies, Dalarna University, 79188 Falun, Sweden \\ ${ }^{3}$ Department of Medical Sciences, Respiratory Medicine and Allergology, Uppsala University, 75105 Uppsala, Sweden \\ ${ }^{4}$ Clinical Epidemiology and Biostatistics, Örebro University Hospital \& School of Health and Medical Science, Örebro University, 70185 Örebro, \\ Sweden \\ ${ }^{5}$ Clinical Epidemiology Unit, Department of Medicine, Karolinska University Hospital, Karolinska Institute, 17176 Stockholm, Sweden \\ ${ }^{6}$ Department of Public Health and Caring Science, Family Medicine and Preventive Medicine, Uppsala University, 75122 Uppsala, Sweden \\ + Eva Österlund Efraimsson deceased May 2013
}

Received 11th March 2013; revised 2nd June 2013; accepted 18th June 2013; online 10th October 2013

\begin{abstract}
Background: Chronic obstructive pulmonary disease (COPD) exacerbations are associated with lung function decline, lower quality of life, and increased mortality, and can be prevented by pharmacological treatment and rehabilitation.

Aims: To examine management including examination, treatment, and planned follow-up of COPD exacerbation visits in primary care patients and to explore how measures and management at exacerbation visits are related to subsequent exacerbation risk.

Methods: A clinical population of 775 COPD patients was randomly selected from 56 Swedish primary healthcare centres. Data on patient characteristics and management of COPD exacerbations were obtained from medical record review and a patient questionnaire. In the study population of 458 patients with at least one exacerbation, Cox regression analyses estimated the risk of a subsequent exacerbation with adjustment for age and sex.

Results: During a follow-up period of 22 months, 238 patients (52\%) had a second exacerbation. A considerable proportion of the patients were not examined and treated as recommended by guidelines. Patients with a scheduled extra visit to an asthma/COPD nurse following an exacerbation had a decreased risk of further exacerbations compared with patients with no extra follow-up other than regularly scheduled visits (adjusted hazard ratio 0.60 (95\% confidence interval 0.37 to 0.99), $p=0.045$ ).

Conclusions: Guidelines for examination and emergency treatment at COPD exacerbation visits are not well implemented. Scheduling an extra visit to an asthma/COPD nurse following a COPD exacerbation may be associated with a decreased risk of further exacerbations in primary care patients.

(C) 2013 Primary Care Respiratory Society UK. All rights reserved.

J Sundh et al. Prim Care Respir J 2013; 22(4): 393-399

http://dx.doi.org/10.4104/pcrj.2013.00087
\end{abstract}

Keywords primary care, COPD, exacerbation, management, nurse

\section{Introduction}

Chronic obstructive pulmonary disease (COPD) exacerbations are a major global cause of morbidity., ${ }^{1,2}$ They are known to cause lung function decline, ${ }^{1}$ frequent hospital admission ${ }^{2}$ generating a substantial financial burden for society, ${ }^{3}$ worsening quality of life, ${ }^{4,5}$ and increased mortality. ${ }^{2,6,7}$ Previous studies have shown that exacerbation risk can be reduced by pharmacological ${ }^{8-10}$ and nonpharmacological ${ }^{11,12}$ interventions during the stable phase.

International guidelines for COPD exacerbations recommend careful examination and treatment with inhaled bronchodilators, antibiotics, and oral steroids. ${ }^{13-15}$ Studies of exacerbation management in hospitalised COPD patients have shown that

\footnotetext{
* Corresponding author: Dr Josefin Sundh, Department of Respiratory Medicine, Örebro University Hospital \& School of Health and Medical Science, Örebro University, 70185 Örebro, Sweden. Tel +46 196025597, +46 702349517 Fax +46 19186526 E-mail: josefin.sundh@orebroll.se
} 
management is not always optimal, ${ }^{16,17}$ indicating a need to explore the management of COPD exacerbations in primary care patients.

In Sweden, management of the majority of COPD patients involves regular visits in primary care and a smaller number involves regular visits to secondary care outpatient clinics. ${ }^{18}$ During acute exacerbations, patients with regular visits in primary care might present either at their primary healthcare centre (PHCC) or in the accident and emergency department of the nearest hospital.

The first aim of this study was to examine the management of exacerbations in Swedish primary care COPD patients during emergency visits in PHCCs or in hospitals by describing examinations, treatment, and planned follow-up. The second aim was to study the associations of these measures with the risk of a subsequent exacerbation.

\section{Methods}

\section{Setting}

In Sweden it is recommended that PHCCS have a specific asthma/COPD clinic with access to spirometry, pulse oximeters, nebulisers, and oxygen. ${ }^{19}$ Each general practitioner (GP) is responsible for the diagnosis, treatment, and follow-up of COPD patients and can refer patients to the asthma/COPD clinic for spirometry and patient education. A Swedish asthma/COPD clinic should involve a responsible GP and a trained specialist nurse. ${ }^{18-21}$ The role of the asthma/COPD nurse is to perform and interpret spirometry, peak expiratory flow (PEF) and pulse oximetry, to provide patient education comprising pathophysiology, treatment, inhalation technique and smoking cessation, ${ }^{22}$ and to cooperate with the patient's GP in planning treatment and follow-up. ${ }^{21}$ In secondary care, an asthma/COPD nurse is often available for outpatients.

\section{Population and data collection}

Participants were sampled from a larger cohort of COPD patients at 56 PHCCs in seven Swedish counties. ${ }^{23-26}$ Data were obtained from medical record review and a patient questionnaire, and the procedures are presented in Figure 1. The final study population included the $458(59.1 \%)$ primary care COPD patients who

\section{Figure 1. Patient population flow chart}

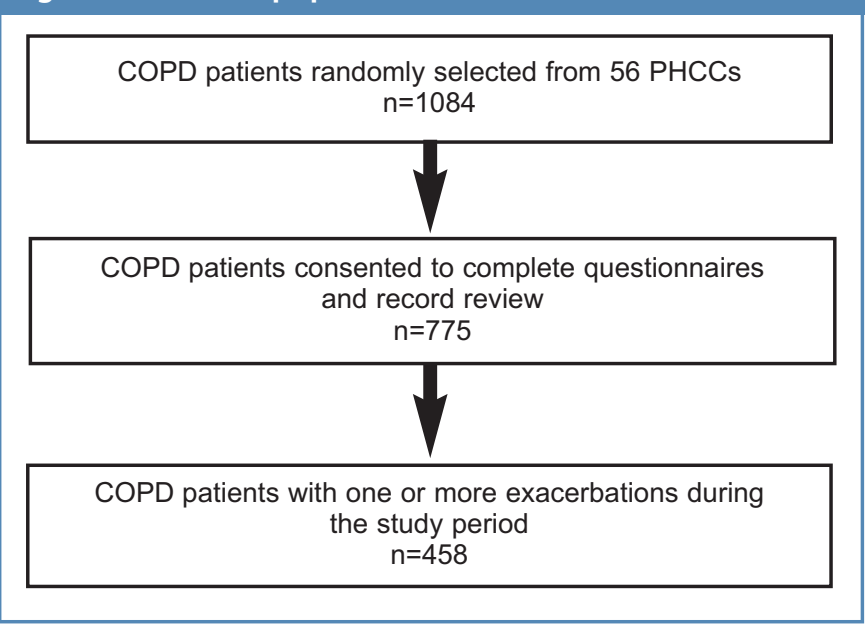

PRIMARY CARE RESPIRATORY JOURNAL

Www.thepcrj.org presented with one or more exacerbations in PHCCs or at the accident and emergency department of a hospital during 20002003. Information on exacerbation visits was obtained using records from both PHCCs and nearby hospitals. Information on clinical resources was obtained in 2005 using a clinical questionnaire to the clinical directors of the participating centres.

\section{Measures}

Sex, age, level of education, and smoking status were obtained from patient questionnaires. The dichotomous education variable identified education for at least two years beyond the compulsory period of nine years. Information about co-morbidity, lung function, and exacerbations was obtained from medical records. All first and second exacerbations were identified by careful record review of characteristics of patient visits. An exacerbation was defined as an unscheduled or emergency visit at a PHCC or hospital due to increased dyspnoea, increased cough, increased sputum production, purulent sputum, or an airway infection. In addition, the visit should result in either treatment with oral or parenteral steroids, inhalation using nebulised bronchodilators, treatment with antibiotics, hospital admission due to COPD symptoms, or alteration to maintenance or rescue medication. A minimum of 14 days was the defined period between exacerbations, as previously used in a Swedish study. ${ }^{27}$ Information was collected on examination, treatment, and planned extra follow-up at exacerbation visits (Table 1). Heart disease (ischaemic heart disease or heart failure), type 1 or 2 diabetes mellitus, and depression (diagnosis combined with pharmaceutical therapy) were identified. Lung function data were available for 184 patients (40.2\%). Forced expiratory volume in one second (FEV 1 ) was expressed as percentage of predicted using the European Community for Steel and Coal reference value. ${ }^{28}$ The subgroup of patients with spirometry data was divided by COPD stage according to the Global Initiative for Chronic Obstructive Lung Disease (GOLD) recommendations. ${ }^{15}$ Information about nurse-led asthma/COPD clinics, nebulisers, pulse oximeters, and spirometers was obtained from the clinical questionnaires.

\section{Statistical analysis}

The analyses were performed using PASW Version 20.0 (SPSS Inc, Chicago, Illinois, USA) and Stata (StataCorp LP, College Station, Texas, USA). Cross-tabulations and the $\chi^{2}$ test examined differences in measures at exacerbation visits in primary versus secondary care, and between patients with one and more than one exacerbation visits. Kaplan-Meier and Cox regression analyses assessed time from first to second exacerbation, with adjustment for age and sex. The proportional hazards assumption was violated for the following measures: added rescue medication, altered maintenance treatment, and extra scheduled visits to nurse and doctor as tested by Schoenfeld residuals and graphically. For this reason, all analyses were right-truncated for follow-up to 22 months as hazards were proportional to this time.

The analyses were repeated with further adjustment for lung function in a subgroup of 184 patients with spirometry data. Associations with follow-up by doctor or nurse were further investigated through stratification and interaction by sex, age, prescribed steroid course, and lung function. Hazard ratios (HR) with 


\begin{tabular}{|c|c|c|c|c|}
\hline Examinations and measures & $N(\%)$ & $\begin{array}{l}\text { Exacerbation } \\
\text { visit PHCC } \\
(\mathrm{n}=391,85 \%)\end{array}$ & $\begin{array}{l}\text { Exacerbation } \\
\text { visit hospital } \\
(n=67,15 \%)\end{array}$ & p Value \\
\hline \multicolumn{5}{|l|}{ PEF } \\
\hline Before inhalation of bronchodilators & $213(47.5 \%)$ & $179(46.9 \%)$ & $34(51.5 \%)$ & 0.484 \\
\hline After inhalation of bronchodilators & $121(26.6 \%)$ & $103(26.4 \%)$ & $18(27.7 \%)$ & 0.829 \\
\hline Saturation & $65(14.3 \%)$ & $18(4.6 \%)$ & $47(72.3 \%)$ & $<0.0001$ \\
\hline Lung auscultation & $440(96.7 \%)$ & $375(96.4 \%)$ & $65(98.5 \%)$ & 0.381 \\
\hline Heart rate & $135(29.6 \%)$ & $82(21.0 \%)$ & $53(80.3 \%)$ & $<0.0001$ \\
\hline Arterial blood gas & $23(5.0 \%)$ & $1(0.3 \%)$ & $22(33.3 \%)$ & $<0.0001$ \\
\hline X-ray lungs & $64(14.0 \%)$ & $30(7.7 \%)$ & $34(51.5 \%)$ & $<0.0001$ \\
\hline CRP & $237(52.0 \%)$ & $191(49.0 \%)$ & $46(69.7 \%)$ & 0.002 \\
\hline Electrocardiogram & $37(8.1 \%)$ & $20(5.1 \%)$ & $17(25.8 \%)$ & $<0.0001$ \\
\hline Hospital admission or acute referral to hospital & $39(8.6 \%)$ & $12(3.1 \%)$ & $27(40.9 \%)$ & $<0.0001$ \\
\hline Inhaled nebulised bronchodilators & $186(40.6 \%)$ & $144(36.8 \%)$ & $42(62.7 \%)$ & $<0.0001$ \\
\hline Course of steroids & $128(27.9 \%)$ & $93(23.8 \%)$ & $35(52.2 \%)$ & $<0.0001$ \\
\hline Course of antibiotics & $274(59.8 \%)$ & $233(59.6 \%)$ & $41(61.2 \%)$ & 0.805 \\
\hline \multicolumn{5}{|l|}{ Planned extra follow-up } \\
\hline No extra visit & $324(70.7 \%)$ & $278(71.1 \%)$ & $46(68.7 \%)$ & Ref \\
\hline Extra visit or call doctor & $86(18.8 \%)$ & $65(16.6 \%)$ & $21(31.3 \%)$ & 0.034 \\
\hline Extra visit nurse & $48(10.5 \%)$ & $48(12.3 \%)$ & $0(0 \%)$ & $<0.0001$ \\
\hline
\end{tabular}

Examinations performed and measures taken at exacerbation visit 1 according to medical records, in total and distributed over level of care.

$C R P=C$ reactive protein, $\mathrm{PEF}=$ peak expiratory flow.

95\% confidence intervals $(95 \% \mathrm{Cl}$ ) were presented and a p value $<0.05$ was considered statistically significant.

\section{Ethics}

The study was approved by the Regional Ethical Review Board of Uppsala University (Dnr 2010/090). Written consent to use the information for future analysis was obtained for all participating patients in 2005.

\section{Results}

A median number of 2 (range 1-49) exacerbations was observed over the four-year study period, and the distribution is presented in Figure

\section{Figure 2 Number of exacerbation visits}

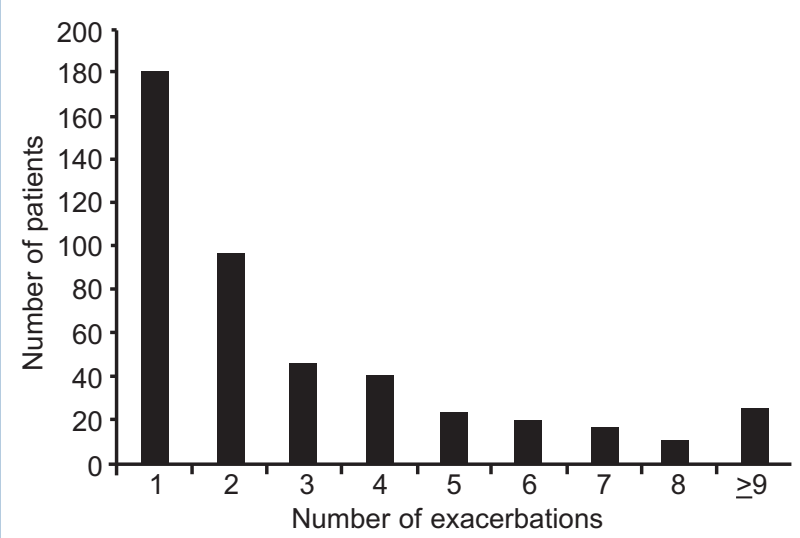

Total number of exacerbations among patients with at least one exacerbation during the study period of four years.
2. Examinations and prescriptions by first emergency visit in a PHCC and in a hospital are described in Table 1 and Figure 3.

Of the 458 patients with at least one exacerbation, 238 patients had a second exacerbation within 22 months (Table 2 ). The analyses were repeated without the 22-month right-truncation with no material alteration of the results (data not shown). Table 2 shows the characteristics of patients with one or more than one exacerbations.

Female sex and treatment with a course of oral steroids were both statistically significantly and independently associated with an increased risk of a subsequent exacerbation (Table 3). Added maintenance and rescue medication and an extra planned visit to a

\section{Figure 3 Emergency at therapy exacerbation visits}

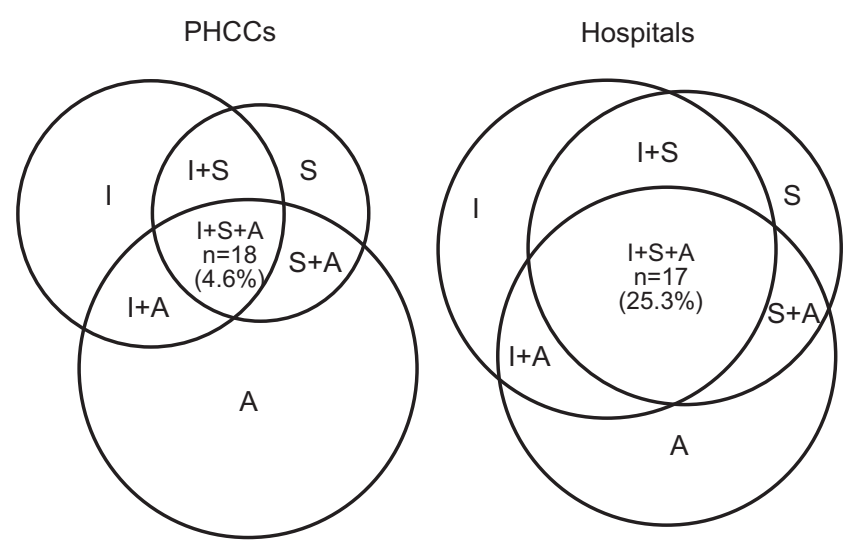

PHCCs=Primary health care centers. I=Inhaled nebulised bronchodilators, $S=$ Steroid course, $A=$ Antibiotic course. 


\begin{tabular}{|c|c|c|c|}
\hline $\begin{array}{l}\text { Characteristics and } \\
\text { measures }\end{array}$ & $\begin{array}{l}\text { Patients with } \\
1 \text { exacerbation }\end{array}$ & $\begin{array}{l}\text { Patients with } \\
\geq 2 \text { exacerbations }\end{array}$ & $\begin{array}{l}\mathrm{p} \\
\text { Value }\end{array}$ \\
\hline All $(n=458)$ & $220(48 \%)$ & $238(52 \%)$ & \\
\hline \multicolumn{4}{|l|}{$\operatorname{Sex}(n=458)$} \\
\hline Male & $92(41.8 \%)$ & $73(30.7 \%)$ & Ref \\
\hline Female & $128(58.2 \%)$ & $165(69.3 \%)$ & 0.013 \\
\hline \multicolumn{4}{|l|}{ Educational level* } \\
\hline Lower & $151(69.6 \%)$ & $169(72.8 \%)$ & Ref \\
\hline Higher & $66(30.4 \%)$ & $63(27.2 \%)$ & 0.446 \\
\hline \multicolumn{4}{|l|}{ Current daily smoker** } \\
\hline No & $146(66.7 \%)$ & $165(69.3)$ & Ref \\
\hline Yes & $73(33.3 \%)$ & $73(30.7 \%)$ & 0.542 \\
\hline \multicolumn{4}{|l|}{ Age (years) } \\
\hline$<50$ & $18(8.2 \%)$ & $16(6.7 \%)$ & 0.876 \\
\hline $51-60$ & $51(23.2 \%)$ & $60(25.2 \%)$ & 0.204 \\
\hline $61-70$ & $90(40.9 \%)$ & $111(46.6 \%)$ & 0.101 \\
\hline$>70$ & $61(27.7 \%)$ & $51(21.4 \%)$ & Ref \\
\hline \multicolumn{4}{|l|}{ Comorbidity } \\
\hline Heart disease & $50(22.7 \%)$ & $45(18.9 \%)$ & 0.314 \\
\hline Depression & $35(15.9 \%)$ & $32(13.4 \%)$ & 0.456 \\
\hline Diabetes & $19(8.6 \%)$ & $23(9.2 \%)$ & 0.703 \\
\hline \multicolumn{4}{|l|}{ Lung function $* \star \star$} \\
\hline Stage 1 & $38(42.2 \%)$ & $22(23.4 \%)$ & Ref \\
\hline Stage 2 & $30(33.3 \%)$ & $41(43.6 \%)$ & 0.017 \\
\hline Stage 3 & $20(22.2 \%)$ & $27(28.7 \%)$ & 0.034 \\
\hline Stage 4 & $2(2.2 \%)$ & $4(4.3 \%)$ & 0.171 \\
\hline \multicolumn{4}{|l|}{$\begin{array}{l}\text { Level of care } \\
\text { exacerbation visit } 1\end{array}$} \\
\hline PHCC & $197(89.5 \%)$ & $194(81.5 \%)$ & Ref \\
\hline Hospital & $23(10.5 \%)$ & $44(18.5 \%)$ & 0.015 \\
\hline Added maintenance therapy & $76(34.5 \%)$ & $51(21.4 \%)$ & 0.002 \\
\hline Added rescue therapy & $28(12.7 \%)$ & $14(5.9 \%)$ & 0.011 \\
\hline Acute inhalation therapy & $90(40.9 \%)$ & $96(40.6 \%)$ & 0.901 \\
\hline Course of steroids & $46(20.9 \%)$ & $82(34.5 \%)$ & 0.001 \\
\hline Course of antibiotics & $128(58.2 \%)$ & $146(61.3 \%)$ & 0.490 \\
\hline \multicolumn{4}{|l|}{ Planned extra follow-up } \\
\hline No extra visit & $147(66.8 \%)$ & $177(74.4 \%)$ & Ref \\
\hline Extra visit or call doctor & $43(19.5 \%)$ & $43(18.1 \%)$ & 0.444 \\
\hline Extra visit nurse & $30(13.6 \%)$ & $18(7.6 \%)$ & 0.029 \\
\hline
\end{tabular}

Study period truncated at 22 months.

Number with available information: ${ }^{*} n=449,{ }^{* *} n=457, * * * n=184$.

nurse compared with no extra scheduled visits were statistically significantly and independently associated with a decreased risk of a subsequent exacerbation (Table 3, Figure 4).

When examining only patients with the first visit in primary care, the HR for the association between an extra planned visit to a nurse and reduced risk for subsequent exacerbation was $0.64(95 \% \mathrm{Cl}$ 0.39 to 1.05$), p=0.077$.

In the subgroup of 184 patients with lung function data, the association of a steroid course with increased risk of a new exacerbation remained both after adjustment for sex and age (HR 1.94 (95\% Cl 1.25 to 3.02), $\mathrm{p}=0.003$ ) and additional adjustment for
Figure 4 Planned follow-up and time to second exacerbation

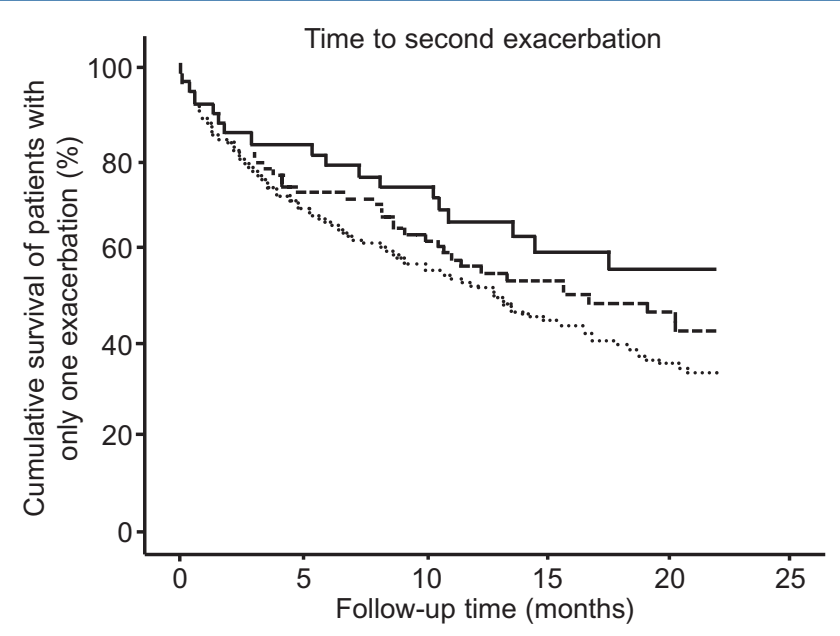

Kaplan-Meier curves for extra planned follow-up by doctor or nurse compared with no extra scheduled visits.

Solid line = extra planned visit to nurse, broken line = extra planned visit or telephone call by doctor, dotted line $=$ no extra scheduled visits.

lung function ( $\mathrm{HR} 1.88(95 \% \mathrm{Cl} 1.20$ to 2.94), $\mathrm{p}=0.006)$. The association of female sex with a higher risk of a subsequent exacerbation remained after adjustment for age (HR $1.65(95 \% \mathrm{Cl}$ 1.04 to 2.61), $p=0.032$ ) and was somewhat attenuated after adjustment for lung function (HR $1.59(95 \% \mathrm{Cl} 1.01$ to 2.52), $\mathrm{p}=0.050$ ). The same pattern was shown for an extra planned visit to a nurse; the association with a reduced exacerbation risk was statistically significant after adjustment for age and sex (HR 0.48 ( $95 \% \mathrm{Cl} 0.25$ to 0.91 ), $\mathrm{p}=0.025$ ) but not after additional adjustment for lung function (HR $0.55(95 \% \mathrm{Cl} 0.28$ to 1.07$), p=0.77)$. The associations with the risk of a second exacerbation for added rescue medication and maintenance medication were eliminated by further adjustment for lung function (data not shown). Higher COPD stage was associated with a higher risk of a subsequent exacerbation (data not shown).

Patients treated with a steroid course statistically significantly more often had a planned follow-up by a doctor (39.5\%) than by a nurse $(20.8 \%)(p=0.027 ; p$ for interaction=0.043). Stratification and interaction analyses by sex, age, and lung function showed no differences in the adjusted associations with second exacerbation risks for extra scheduled visits to a doctor or nurse (data not shown).

The clinical questionnaire revealed that 36 of the participating 56 PHCCs (64\%) and seven of the 14 secondary care clinics (50\%) had a specific nurse-led asthma/COPD clinic. In the PHCCs, nebulisers for inhalation of bronchodilators were available in 50 centres (89\%), pulse oximeters in 46 centres ( $82 \%)$, and spirometers in 52 centres (93\%). All 14 secondary care clinics had access to pulse oximetry and nebulisers, and $13(93 \%)$ had their own spirometer.

\section{Discussion}

\section{Main findings}

The main finding of this multicentre study of primary care COPD 
Table 3. Cox regression analyses for preventive measures

\begin{tabular}{|c|c|c|c|c|}
\hline Characteristics and measures & Unadjusted HR (95\% Cl) & p Value & Adjusted HR (95\% Cl) & $\mathrm{p}$ Value \\
\hline \multicolumn{5}{|l|}{ Sex } \\
\hline Male & Ref & & Ref & \\
\hline Female & $1.40(1.06$ to 1.85 & 0.016 & $1.40(1.06$ to 1.86$)$ & 0.019 \\
\hline Acute inhalation treatment & $1.14(0.88$ to 1.48$)$ & 0.307 & $1.16(0.89$ to 1.50$)$ & 0.267 \\
\hline Course of steroids & 1.56 (1.19 to 2.04$)$ & 0.001 & 1.58 (1.21 to 2.07$)$ & 0.001 \\
\hline Course of antibiotics & $1.08(0.83$ to 1.40$)$ & 0.580 & $1.05(0.81$ to 1.36$)$ & 0.734 \\
\hline Added rescue treatment & $0.54(0.31$ to 0.93$)$ & 0.025 & $0.53(0.31$ to 0.91$)$ & 0.022 \\
\hline Added maintenance treatment & $0.72(0.53$ to 0.98$)$ & 0.038 & $0.73(0.54$ to 1.00$)$ & 0.048 \\
\hline \multicolumn{5}{|l|}{ Planned extra follow-up } \\
\hline No extra scheduled visit & Ref & & Ref & \\
\hline Extra visit or call to doctor & $0.81(0.58$ to 1.13$)$ & 0.214 & $0.82(0.59$ to 1.15$)$ & 0.254 \\
\hline Extra visit nurse & $0.58(0.36$ to 0.94$)$ & 0.026 & $0.60(0.37$ to 0.99$)$ & 0.045 \\
\hline
\end{tabular}

patients is that a considerable proportion of patients consulting for an exacerbation were not examined, treated, and planned for follow-up as recommended in the guidelines.

Furthermore, we found that female sex and treatment with steroid courses were associated with a higher risk of a subsequent exacerbation, and that added rescue or maintenance medication and an extra planned visit to an asthma/COPD nurse following an exacerbation were associated with a reduced risk of subsequent exacerbations.

\section{Interpretation of findings in relation to previously published work}

Interestingly, not only patients in COPD stage 3 but also those in stage 2 statistically significantly more often had two or more exacerbations compared with patients in COPD stage 1. Thus, even patients with moderate disease might often have exacerbations, which supports the intention of the recent GOLD updates to consider exacerbation frequency as well as symptoms and lung function when assessing the disease..$^{15}$ The number of patients in stage 4 is too small to draw firm conclusions.

National and international guidelines support careful examination at exacerbation visits. ${ }^{13-15}$ This study suggests that management should be improved - especially with respect to measuring oxygen saturation and heart rate - in order to identify patients with severe exacerbations in need of hospital admission. Recommendations were better followed when primary care patients with exacerbations were managed in hospitals, but management was not optimal at any level of care.

It is interesting that courses of oral steroids and nebulised bronchodilators were more often used in secondary care while antibiotics were equally common in primary and secondary care. The difference in treatment of exacerbations in PHCCs and hospitals might at least partly reflect differences in the severity of the exacerbations, but is still unexpected. However, treating exacerbations with antibiotics and steroids is evidence-based ${ }^{29-32}$ and recommended in international guidelines. ${ }^{13-15}$ Our study showed no association between treatment with antibiotics and subsequent exacerbation, and an increased risk of treatment with a course of oral steroids. We believe that this is at least partly because the patients receiving steroids had more severe disease with greater risk of new exacerbations.
Our findings are consistent with studies of exacerbation management in hospitalised COPD patients, ${ }^{16,17}$ but we are not aware of other similar studies describing the management of COPD exacerbations in primary care patients in both PHCCs and hospitals.

Women are known to have an increased susceptibility to develop COPD. ${ }^{33}$ Biological explanations such as through hormones have been suggested. ${ }^{34}$ The association with a higher risk for a subsequent exacerbation among women in this study is consistent with several studies of secondary care patients $s^{35,36}$ but has not been shown previously for primary care patients.

Information from the clinical questionnaires revealed that only about two-thirds of the participating PHCCs and about half of the participating hospital clinics in this study had specific nurse-led asthma/COPD clinics. A Swedish study examining resources in PHCCs in western Sweden found that $82 \%$ of PHCCs had a nurse specifically responsible for COPD, ${ }^{37}$ and a more recent Swedish study found that the proportion of asthma/COPD clinics was even higher (87\%). ${ }^{18}$ In the same studies, the presence of pulse oximeters and nebulisers was equal or slightly higher than in our study. Since our study examines management in an earlier calendar period than the other Swedish studies, this indicates that national recommendations regarding structure of COPD care have been better implemented over time.

The organisation of COPD care has been studied in several countries. Nurse-led asthma/COPD clinics are common in the UK, ${ }^{38,39}$ and nurse-based information programmes have been used in the Netherlands with a beneficial effect on exacerbation frequency..$^{40} \mathrm{An}$ integrated care system including a nurse case manager associated with a reduced risk of hospital admissions due to COPD exacerbations has been described in Spain and Belgium. ${ }^{41}$ A previous meta-analysis in the UK examined nurse-led management interventions for COPD with no certain positive effects. ${ }^{42}$ However, the organisation of nurseled asthma/COPD clinics might differ between countries. Our finding that an extra scheduled visit to a nurse after an exacerbation might be associated with a reduced risk of a subsequent exacerbation is consistent with a Swedish study where patients in PHCCs with nurseled asthma/COPD clinics had fewer exacerbations. ${ }^{18}$

A possible explanation for the decreased exacerbation risk following an extra scheduled visit to a nurse could be selection bias, if patients chosen for follow-up by nurse were generally healthier 
than patients with planned doctor follow-up. This could be consistent with the higher rate of steroid courses among those with planned follow-up by a doctor. On the other hand, COPD stage did not differ significantly between the doctor and nurse follow-up groups. Thus, our findings are unlikely to be explained entirely by selection bias.

Another possible explanation is that patients with a first exacerbation visit at a hospital could have more severe exacerbations and none of these patients had an extra planned nurse visit. A subanalysis of patients with the first exacerbation visit in a PHCC was examined. This resulted in a HR of similar magnitude but was no longer statistically significant, which is partially explained by reduced power due to fewer patients. We believe that exacerbation visits at hospitals do not necessary signal more severe exacerbations. In Sweden, primary care patients have limited access to GPs during evenings and weekends and so may present at hospitals.

We believe the association between an extra planned nurse visit could indicate reactivity of the PHCC management team to the exacerbation to optimise care. It could be a marker for generally better COPD care with integrated management. The nurse may have more time to develop a comprehensive view of the patient and help to implement strategies to reduce exacerbation risk.

\section{Strengths and limitations}

Strengths of this study are that it is longitudinal and comprises a real clinical population of COPD patients without exclusion criteria, randomly sampled from multiple centres. This ensures a high level of generalisability. Further, the data from medical records were initially recorded prospectively and should be reliable and not subject to different recall bias.

A limitation is that lung function data were only available for a subset of the study population, although most clinics had access to spirometry. Possible explanations might be that spirometry had been performed but not reported in the records or that patients had a diagnosis confirmed by spirometry before the study. Patients with severe disease might have been particularly unable or unwilling to perform a lung function test. It has been demonstrated that many COPD diagnoses are based on clinical findings rather than spirometry. ${ }^{23}$

We did not have access to records prior to the study period 20002003 so earlier spirometry data were unavailable. Another potential issue is that $32 \%$ of the spirometry measurements were based on pre-bronchodilator values but we speculate that, in most of these cases, spirometry with reversibility test had also been performed previously.

Only exacerbation visits in PHCCs and hospitals in the seven counties of the study area were examined. However, we believe that failure to identify exacerbation visits abroad or in other parts of the country must constitute a very small number, not influencing the results of the study. COPD exacerbations may sometimes be labelled and treated incorrectly, and we may have missed some exacerbations or included non-exacerbation events. However, our standardised definition should ensure accurate identification of the vast majority of exacerbations. The exacerbations were not graded by severity, but our definition captured exacerbations associated with a healthcare visit and prescribed treatment, indicating severity relevant to use of healthcare resources and patient well-being.

Finally, in our investigation of extra planned visits we cannot be certain that the visits occurred. However, we believe an extra scheduled visit could still serve as a surrogate marker for fulfilled visits and responsive COPD management.

Implications for future research, policy and practice

This study shows that the guidelines for exacerbation management should be better implemented, especially in PHCCs where the majority of exacerbation visits among primary care patients take place. Previous studies have shown that educational programmes of management in stable COPD have improved compliance with guidelines, ${ }^{43,44}$ and it should also be possible to apply this to the management of exacerbations.

The issue of how COPD care should be organised is very important, and this study showed that very few patients were scheduled for extra follow-up. We believe that the finding that an extra scheduled visit to a nurse is as good as a scheduled visit to a doctor and even might reduce the risk of subsequent exacerbation is important and could be a way of optimising resources in COPD care. However, the findings should be confirmed in appropriate studies with adequate statistical power.

\section{Conclusions}

Guidelines for management of COPD exacerbation visits are not followed optimally and ought to be better implemented. Integrated management including nurse-led asthma/COPD clinics might assist in optimising COPD care relevant to exacerbation risk.

\section{Handling editor Arnulf Langhammer Statistical review Gopal Netuveli}

Acknowledgements The authors thank Ulrike Spetz-Nyström and Eva Manell for reviewing the patient records, and all participating centres.

Conflicts of interest The authors declare that they have no conflicts of interest in relation to this article. BS is an Associate editor of the $P C R J$, but was not involved in the editorial review of, nor the decision to publish, this article.

Contributorship All authors made substantial contributions to the conception and design of the study and editing of the manuscript and all authors have approved the submitted paper. CJ is the guarantor of the study.

Funding The study was supported by grants from the county councils of the Uppsala-Örebro Health Care region, the Swedish Heart and Lung Association, the Swedish Asthma and Allergy Association, the Bror Hjerpstedts Foundation, and the Örebro Society of Medicine.

\section{References}

1. Donaldson GC, Seemungal TA, Bhowmik A, Wedzicha JA. Relationship between exacerbation frequency and lung function decline in chronic obstructive pulmonary disease. Thorax 2002;57(10):847-52. http://dx.doi.org/10.1136/thorax.57.10.847

2. Wedzicha JA, Seemungal TA. COPD exacerbations: defining their cause and prevention. Lancet 2007;370(9589):786-96 http://dx.doi.org/10.1016/S0140-6736(07)61382-8

3. Oostenbrink JB, Rutten-van Molken MP. Resource use and risk factors in high-cost exacerbations of COPD. Respir Med 2004;98(9):883-91. http://dx.doi.org/10.1016/j.rmed.2004.02.013

4. Nishimura K, Sato S, Tsukino M, et al. Effect of exacerbations on health status in subjects with chronic obstructive pulmonary disease. Health Qual Life Outcomes 2009;7:69. http://dx.doi.org/10.1186/1477-7525-7-69

5. Bourbeau J, Ford G, Zackon H, Pinsky N, Lee J, Ruberto G. Impact on patients' health status following early identification of a COPD exacerbation. Eur Respir $J$ 2007;30(5):907-13. http://dx.doi.org/10.1183/09031936.00166606

6. Groenewegen $\mathrm{KH}$, Schols AM, Wouters EF. Mortality and mortality-related factors after hospitalization for acute exacerbation of COPD. Chest 2003;124(2):459-67. 
http://dx.doi.org/10.1378/chest.124.2.459

7. Soler-Cataluna JJ, Martinez-Garcia MA, Roman Sanchez P, Salcedo E, Navarro M, Ochando R. Severe acute exacerbations and mortality in patients with chronic obstructive pulmonary disease. Thorax 2005;60(11):925-31. http://dx.doi.org/10.1136/thx.2005.040527

8. Szafranski W, Cukier A, Ramirez A, et al. Efficacy and safety of budesonide/formoterol in the management of chronic obstructive pulmonary disease. Eur Respir J 2003;21(1):74-81.

http://dx.doi.org/10.1183/09031936.03.00031402

9. Calverley PM, Anderson JA, Celli B, et al. Salmeterol and fluticasone propionate and survival in chronic obstructive pulmonary disease. N Engl J Med 2007;356(8):77589. http://dx.doi.org/10.1056/NEJMoa063070

10. Tashkin DP, Celli B, Senn S, et al. A 4-year trial of tiotropium in chronic obstructive pulmonary disease. N Engl J Med 2008;359(15):1543-54. http://dx.doi.org/10.1056/NEJMoa0805800

11. Griffiths TL, Burr ML, Campbell IA, et al. Results at 1 year of outpatient multidisciplinary pulmonary rehabilitation: a randomised controlled trial. Lancet 2000;355(9201):362-8. http://dx.doi.org/10.1016/\$0140-6736(99)07042-7

12. Puhan MA, Gimeno-Santos E, Scharplatz M, Troosters T, Walters EH, Steurer J. Pulmonary rehabilitation following exacerbations of chronic obstructive pulmonary disease. Cochrane Database Syst Rev 2011;(10):CD005305.

13. Bellamy D, Bouchard J, Henrichsen $S$, et al. International Primary Care Respiratory Group (IPCRG) guidelines: management of chronic obstructive pulmonary disease (COPD). Prim Care Respir J 2006;15(1):48-57. http://dx.doi.org/10.1016/j.pcrj.2005.11.003

14. Yawn BP, Thomashow B. Management of patients during and after exacerbations of chronic obstructive pulmonary disease: the role of primary care physicians. Int J Gen Med 2011;4:665-76. http://dx.doi.org/10.2147/JJGM.S22878

15. Global Initiative for Chronic Obstructive Lung Disease. Global strategy for diagnosis, management, and prevention of COPD 2001 (updated 2013). Available from: http://www.goldcopd.com (accessed 25 March 2013)

16. Lindenauer PK, Pekow P, Gao S, Crawford AS, Gutierrez B, Benjamin EM. Quality of care for patients hospitalized for acute exacerbations of chronic obstructive pulmonary disease. Ann Intern Med 2006;144(12):894-903. http://dx.doi.org/10.7326/0003-4819-144-12-200606200-00006

17. Yip NH, Yuen G, Lazar EJ, et al. Analysis of hospitalizations for COPD exacerbation: opportunities for improving care. COPD 2010;7(2):85-92. http://dx.doi.org/10.3109/15412551003631683

18. Lofdahl CG, Tilling B, Ekstrom T, Jorgensen L, Johansson G, Larsson K. COPD health care in Sweden - a study in primary and secondary care. Respir Med 2010;104(3):404-11. http://dx.doi.org/10.1016/..rmed.2009.10.007

19. Swedish National Board of Health and Welfare. Socialstyrelsens riktlinjer för vård av astma och kroniskt obstruktiv lungsjukdom. Faktadokument och beslutsstöd för prioriteringar. 2004.

20. Kull I, Johansson GS, Lisspers K, et al. [Efficient care in asthma/COPD primary health care clinics]. Lakartidningen 2008;105(42):2937-40.

21. Lisspers K, Stallberg B, Hasselgren M, Johansson G, Svardsudd K. Primary health care centres with asthma clinics: effects on patients' knowledge and asthma control. Prim Care Respir J 2010;19(1):37-44. http://dx.doi.org/10.4104/pcri.2009.00043

22. Efraimsson EO, Hillervik C, Ehrenberg A. Effects of COPD self-care management education at a nurse-led primary health care clinic. Scand I Caring Sci 2008;22(2):178-85. http://dx.doi.org/10.1111/j.1471-6712.2007.00510.x

23. Arne M, Lisspers K, Stallberg B, et al. How often is diagnosis of COPD confirmed with spirometry? Respir Med 2010;104(4):550-6. http://dx.doi.org/10.1016/.rmed.2009.10.023

24. Sundh J, Stallberg B, Lisspers K, Montgomery SM, Janson C. Co-morbidity, body mass index and quality of life in COPD using the Clinical COPD Questionnaire. COPD 2011;8(3):173-81. http://dx.doi.org/10.3109/15412555.2011.560130

25. Sundh J, Janson C, Lisspers K, Stallberg B, Montgomery S. The Dyspnoea, Obstruction, Smoking, Exacerbation (DOSE) index is predictive of mortality in COPD. Prim Care Respir J 2012;21(3):295-301. http://dx.doi.org/10.4104/pcrj.2012.00054

26. Sundh J, Janson C, Lisspers K, Montgomery S, Stallberg B. Clinical COPD Questionnaire score (CCQ) and mortality. Int I Chron Obstruct Pulmon Dis 2012;7:833-42. http://dx.doi.org/10.2147/COPD.S38119

27. Larsson $\mathrm{K}$, Janson C, Lisspers $\mathrm{K}$, et al. Combination of budesonide/formoterol more effective than fluticasone/salmeterol in preventing exacerbations in chronic obstructive pulmonary disease: the PATHOS study. J Intern Med 2013;273(6):58494. http://dx.doi.org/10.1111/joim.12067

28. Quanjer PH, Tammeling GJ, Cotes JE, Pedersen OF, Peslin R, Yernault JC. Lung volumes and forced ventilatory flows. Report Working Party Standardization of Lung Function Tests, European Community for Steel and Coal. Official statement of the European Respiratory Society. Eur Respir I Supp/ 1993;16:5-40.

29. Daniels JM, Snijders D, de Graaff CS, Vlaspolder F, Jansen HM, Boersma WG. Antibiotics in addition to systemic corticosteroids for acute exacerbations of chronic obstructive pulmonary disease. Am J Respir Crit Care Med 2010;181(2):150-7. http://dx.doi.org/10.1164/rccm.200906-08370C

30. Sayiner A, Aytemur ZA, Cirit M, Unsal I. Systemic glucocorticoids in severe exacerbations of COPD. Chest 2001;119(3):726-30. http://dx.doi.org/10.1378/chest.119.3.726

31. Ram FS, Rodriguez-Roisin R, Granados-Navarrete A, Garcia-Aymerich J, Barnes NC. Antibiotics for exacerbations of chronic obstructive pulmonary disease. Cochrane Database Syst Rev 2011;(1):CD004403.

32. Walters JA, Wang W, Morley C, Soltani A, Wood-Baker R. Different durations of corticosteroid therapy for exacerbations of chronic obstructive pulmonary disease. Cochrane Database Syst Rev 2011;(10):CD006897.

33. Gan WQ, Man SF, Postma DS, Camp P, Sin DD. Female smokers beyond the perimenopausal period are at increased risk of chronic obstructive pulmonary disease: a systematic review and meta-analysis. Respir Res 2006;7:52. http://dx.doi.org/10.1186/1465-9921-7-52

34. Sin $\mathrm{DD}$, Cohen SB, Day A, Coxson H, Pare PD. Understanding the biological differences in susceptibility to chronic obstructive pulmonary disease between men and women. Proc Am Thorac Soc 2007;4(8):671-4. http://dx.doi.org/10.1513/pats.200706-082SD

35. Celli B, Vestbo J, Jenkins CR, et al. Sex differences in mortality and clinical expressions of patients with chronic obstructive pulmonary disease: the TORCH experience. Am J Respir Crit Care Med 2011;183(3):317-22. http://dx.doi.org/10.1164/rccm.201004-06650C

36. de Torres JP, Casanova C, Hernandez C, Abreu J, Aguirre-Jaime A, Celli BR. Gender and COPD in patients attending a pulmonary clinic. Chest 2005;128(4):2012-16. http://dx.doi.org/10.1378/chest.128.4.2012

37. Thorn J, Norrhall M, Larsson R, et al. Management of chronic obstructive pulmonary disease (COPD) in primary care: a questionnaire survey in western Sweden. Prim Care Respir J 2008;17(1):26-31. http://dx.doi.org/10.3132/pcr.2008.00008

38. Upton J, Madoc-Sutton H, Sheikh A, Frank TL, Walker S, Fletcher M. National survey on the roles and training of primary care respiratory nurses in the UK in 2006: are we making progress? Prim Care Respir J 2007;16(5):284-90. http://dx.doi.org/10.3132/pcri.2007.00068

39. Worth A, Pinnock H, Fletcher M, Hoskins G, Levy ML, Sheikh A. Systems for the management of respiratory disease in primary care - an international series: United Kingdom. Prim Care Respir J 2011;20(1):23-32. http://dx.doi.org/10.4104/pcrj.2010.00070

40. Rootmensen GN, van Keimpema AR, Looysen EE, van der Schaaf L, de Haan RJ, Jansen HM. The effects of additional care by a pulmonary nurse for asthma and COPD patients at a respiratory outpatient clinic: results from a double blind, randomized clinical trial. Patient Educ Couns 2008;70(2):179-86. http://dx.doi.org/10.1016/j.pec.2007.09.021

41. Casas A, Troosters T, Garcia-Aymerich J, et al. Integrated care prevents hospitalisations for exacerbations in COPD patients. Eur Respir J 2006;28(1):123-30. http://dx.doi.org/10.1183/09031936.06.00063205

42. Taylor SJ, Candy B, Bryar RM, et al. Effectiveness of innovations in nurse led chronic disease management for patients with chronic obstructive pulmonary disease: systematic review of evidence. BMJ 2005;331(7515):485. http://dx.doi.org/10.1136/bmj.38512.664167.8F

43. Lange $\mathrm{P}$, Rasmussen $\mathrm{FV}$, Borgeskov $\mathrm{H}$, et al. The quality of COPD care in general practice in Denmark: the KVASIMODO study. Prim Care Respir J 2007;16(3):174-81. http://dx.doi.org/10.3132/pcri.2007.00030

44. Ulrik CS, Sorensen TB, Hojmark TB, Olsen KR, Vedsted P. Adherence to COPD guidelines in general practice: impact of an educational programme delivered on location in Danish general practices. Prim Care Respir J 2013;22(1):23-8. http://dx.doi.org/10.4104/pcrj.2012.00089

\section{Available online at http://www.thepcrj.org}

